\title{
Estudo Cinético da Cristalização Dinâmica de um Poliéster Líquido-Cristalino Termotrópico com Espaçadores Flexíveis na Cadeia Principal.
}

\author{
Júlia C. A. Martins, Kátia M. Novack e Ailton S. Gomes
}

Resumo: Foi realizado o estudo cinético da cristalização dinâmica de um poliéster líquido-cristalino termotrópico com espaçadores flexíveis na cadeia principal. O objetivo deste estudo foi verificar o mecanismo da cinética de cristalização do poliéster termotrópico semi-flexível através de um método não-isotérmico. O método empregado (método de Ozawa) permitiu descrever a cinética de cristalização dinâmica do poliéster e os valores de $n$ (expoente de Avrami) encontrados correspondem a um crescimento de cristais em forma de feixe sem crescimento esferulítico posterior.

Palavras-chave: Poliéster termotrópico, espaçadores flexíveis, cinética de cristalização dinâmica.

\section{Introdução}

A cristalização térmica é uma das técnicas de cristalização mais importantes. Durante a cristalização sob a ação da temperatura formam-se cristais fibrilares ou lamelares cujo tamanho e arranjo, dependendo das condições de cristalização, podem originar estruturas tipo feixe, as quais eventualmente se transformam em esferulitos ${ }^{[1,3]}$.

A cinética do processo isotérmico de cristalização em polímeros é feita em termos da equação de Avrami $^{[4]}$. Até 1988, nenhuma investigação sobre a cinética de cristalização de polímeros termotrópicos, com espaçadores flexíveis na cadeia principal, tinha sido relatada na literatura. Porém, a partir da década de 90 com o interesse crescente na área de polímeros líquido-cristalinos, o estudo da cinética de cristalização desses materiais começou a ser realizado.
Atualmente, um método que vem sendo usado com sucesso na determinação do expoente de Avrami, para vários polímeros convencionais de interesse tecnológico, e começa agora a ser utilizado na investigação da cinética de cristalização dinâmica de polímeros termotrópicos é o que foi desenvolvido por Ozawa $^{[5]}$. O modelo proposto por este autor assume que a cristalização ocorre em uma velocidade de resfriamento constante, $\mathrm{R}$, segundo a equação:

$$
\log \{-\ln [1-\mathrm{X}(\mathrm{T})]\}=\mathrm{Q}-n \log \mathrm{R}
$$

onde $n$ é o expoente de Avrami, Q é um parâmetro que é função da velocidade de cristalização no resfriamento e X(T) é a fração de material cristalizado.

Se a teoria de Ozawa for válida, o gráfico de $\log \{-\ln [1-\mathrm{X}(\mathrm{T})]\}$ versus $\log \mathrm{R}$ em uma determinada temperatura, T, fornecerá retas. Os parâmetros $n$ e Q poderão ser obtidos da inclinação e da interseção das 
retas com os eixos das ordenadas, respectivamente.

A cinética de cristalização dinâmica pode ser avaliada através da equação de Ozawa, em um estudo cinético realizado em um calorímetro diferencial de varredura, para diferentes velocidades de resfriamento.

A maioria dos polímeros é processada sob condições não-isotérmicas. Portanto, o estudo da cristalização dinâmica é muito importante já que este tipo de cristalização se aproxima muito das condições reais de processamento do polímero tais como extrusão, moldagem, fiação no estado fundido, etc, e é de grande interesse tecnológico.

Lópes e Wilkes ${ }^{[6]}$ estudaram através da teoria de Ozawa a cinética de cristalização não-isotérmica de várias amostras de poli(sulfeto de p-fenileno), com diferentes pesos moleculares. Todas as amostras analisadas obedeceram à teoria de Ozawa e permitiram estimar o expoente de Avrami sob condições não-isotérmicas.

Outros pesquisadores ${ }^{[7]}$ analisaram o comportamento da cristalização dinâmica de poli(éter-étercetona) e observaram que a análise de Ozawa não descrevia adequadamente a cinética de cristalização não-isotérmica, como já tinha sido verificado anteriormente por outro grupo de pesquisas ${ }^{[8]}$ no caso de polietileno de alta densidade. Porém, esse mesmo grupo também verificou que para polipropileno isotático, a teoria de Ozawa é válida, ou seja, em polímeros onde o processo de cristalização secundária é muito importante, a teoria de Ozawa costuma não satisfazer a investigação cinética.

Em estudo realizado por Liu e Lee ${ }^{[9]}$, sobre a cinética de cristalização não-isotérmica, foi verificado que o comportamento anisotrópico das fases nemática e esmética de poliésteres termotrópicos, com espaçadores metilênicos na cadeia principal, é dependente da velocidade de resfriamento. Foi verificado também que para faixas de temperatura altas, a cinética de cristalização não satisfaz a teoria de Ozawa. Porém satisfaz, perfeitamente, para faixas de temperaturas mais baixas.

Poucos trabalhos foram registrados na literatura sobre o processo de cristalização dinâmica e se concentram na cristalização de polímeros mais convencionais de natureza não-mesomórfica. Neste trabalho, foi realizado o estudo da cinética de cristalização nãoisotérmica de um poliéster termotrópico com grupos oxietilênico e metilênico na cadeia principal, onde foi verificada a cinética de transformação do estado mesomórfico para a fase sólida.

\section{Experimental}

Microscopia ótica

A textura e a faixa de transição da mesofase foi observada através de um microscópio ótico Reichert equipado com polarizadores cruzados e placa de aquecimento.

\section{Calorimetria diferencial de varredura}

O equipamento mais utilizado no estudo da cinética de cristalização foi o calorímetro diferencial de varredura da Perkin-Elmer, modelo DSC-7. As análises foram realizadas sob atmosfera de nitrogênio e se utilizou cerca de $8 \mathrm{mg}$ de amostra. As entalpias de transição foram determinadas utilizando o calor de fusão do índio, como padrão de referência, e foram calculadas a partir das áreas dos picos das endotermas e exotermas nas curvas de calorimetria. Os máximos e mínimos das endotermas e exotermas foram tomados como as temperaturas de transição.

\section{Resultados e Discussão}

O poliéster termotrópico foi preparado com grupos metilênico e oxietilênico como espaçadores flexíveis na cadeia principal, empregando a técnica de polimerização em solução em éter difenílico ${ }^{[10]}$. As propriedades termodinâmicas deste polímero foram publicadas recentememte em trabalho anterior ${ }^{[11]}$.

A estrutura molecular do poliéster termotrópico é mostrada abaixo:<smiles>O=C(O)c1ccc(OCCOc2ccc(OCOc3ccc(O)cc3)cc2)cc1</smiles>

O poliéster semi-flexível apresenta comportamento líquido-cristalino e forma mesofase nemática na fusão. A textura birrefringente foi observada através de microscopia ótica na fusão da amostra ${ }^{[10,11]}$.

Em uma análise prévia do comportamento na cristalização do poliéster, a amostra foi submetida a diferentes velocidades de resfriamento desde $20^{\circ} \mathrm{C} / \mathrm{min}$ até $2,5^{\circ} \mathrm{C} / \mathrm{min}$. A amostra foi aquecida no calorímetro em uma velocidade constante e igual a $20^{\circ} \mathrm{C} / \mathrm{min}$ até cerca de $60^{\circ} \mathrm{C}$ acima da temperatura de isotropização e foi mantida nesta temperatura por dez minutos para apagar toda a história térmica inicial. Em seguida, foi resfriada nas seguintes velocidades de resfriamento: $20,10,5$ e $2,5^{\circ} \mathrm{C} / \mathrm{min}$. 


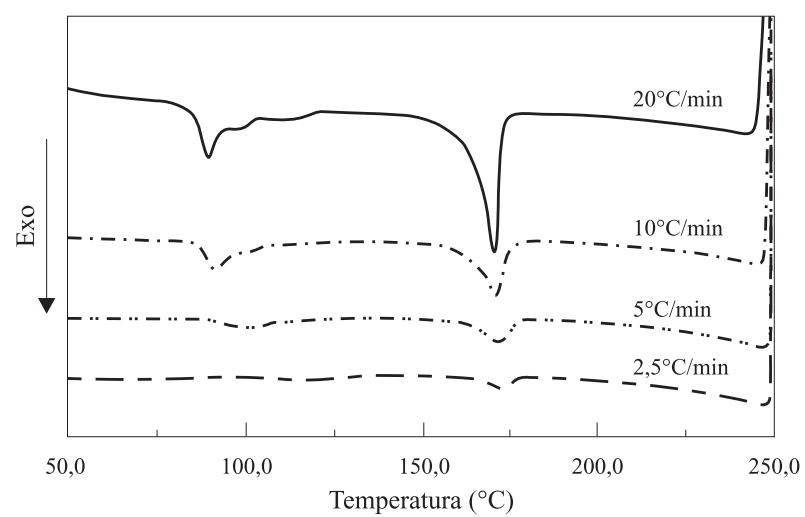

Figura 1. Exotermas de cristalização e desisotropização do poliéster obtidas em diferentes velocidades de resfriamento

$\mathrm{O}$ efeito da velocidade de resfriamento nas curvas de calorimetria diferencial de varredura obtidas no resfriamento da amostra foi analisado. Na Figura 1 estão representadas as duas exotermas das corridas de resfriamento (transição isotrópico-nemático ou desisotropização e transição nemático-sólido ou cristalização) para a amostra com grupos metilênico e oxietilênico na cadeia principal. Das curvas de calorimetria diferencial de varredura do polímero pode ser observado que quando a velocidade de resfriamento diminui as exotermas tendem a se tornar imperceptíveis, ou seja, as alturas relativas dos picos diminuem. O que pode ser concluído é que a transformação se aproxima de uma sucessão de estados de quase-equilíbrio térmico em velocidades de resfriamento muito baixas e portanto, a transição se apresenta de forma mais suave ${ }^{[12]}$. O calorímetro, nessas condições de análise, possivelmente não é capaz de detectar com a mesma precisão as transições sofridas pela amostra.

O poliéster foi submetido ao estudo cinético de cristalização, segundo a teoria de Ozawa. A teoria de Ozawa permitiu identificar a morfologia do polímero através da caracterização do mecanismo de cristalização. Para isso, a amostra foi aquecida em uma velocidade de $40^{\circ} \mathrm{C} / \mathrm{min}$ até uma temperatura acima da temperatura de fusão, onde permaneceu por 10 minutos para apagar a história térmica inicial. Após o cozimento, a amostra foi resfriada em velocidades diferentes no intervalo de 10 a $20^{\circ} \mathrm{C} / \mathrm{min}$ para sofrer então novo aquecimento na mesma velocidade empregada na primeira corrida. As velocidades de resfriamento utilizadas no estudo cinético ficaram dentro de um limite ótimo de sensibilidade do aparelho, permitindo uma análise de precisão. Velocidades de resfriamento muito baixas, menores que $2,5^{\circ} \mathrm{C} / \mathrm{min}$ por exemplo, apresentam sinal de ruído

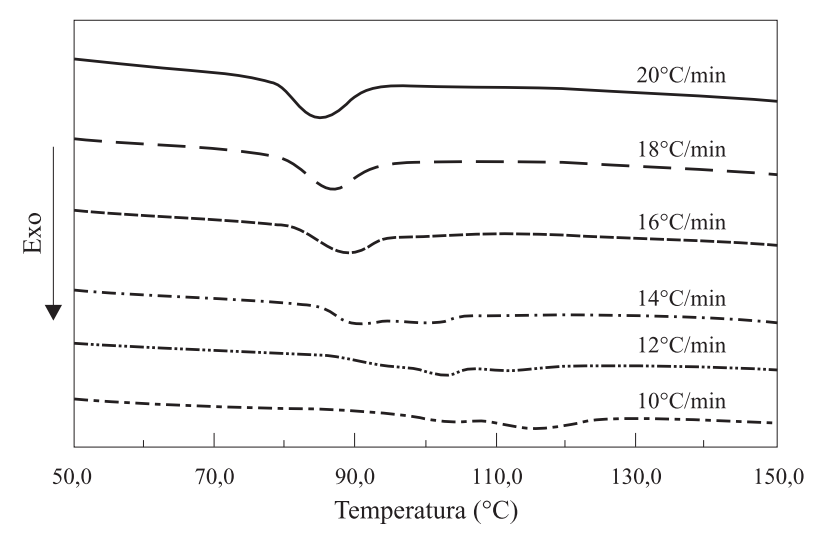

Figura 2. Exotermas de cristalização do poliéster obtidas em diferentes velocidades de resfriamento

devido a menor sensibilidade do calorímetro. Já as velocidades de resfriamento muito altas, maiores que $40^{\circ} \mathrm{C} / \mathrm{min}$, apresentam lentidão no processo de transferência de calor com a amostra ${ }^{[6]}$.

As exotermas representativas da cristalização dinâmica do poliéster em várias velocidades de resfriamento são mostradas na Figura 2. Como pode ser observado, a forma das exotermas se modificou com a velocidade de resfriamento e a partir de uma determinada velocidade de resfriamento surgiu um novo pico que também se deslocou para temperaturas maiores, à medida que a velocidade de resfriamento diminuiu. Após cada resfriamento, foi verificada a influência da velocidade de resfriamento nas endotermas resultantes no segundo aquecimento. Os resultados são mostrados na Tabela 1 .

Foi verificado que as temperaturas de transição na fusão (transição sólido-nemático) e na isotropização (transição nemático-isotrópico) diminuíram com o aumento da velocidade de resfriamento. Os polímeros quando são resfriados mais vagarosamente podem ter sua cristalinidade aumentada e consequentemente, apresentam temperaturas de transição na fusão maiores ${ }^{[12]}$.

Tabela 1. Influência da velocidade de resfriamento nas temperaturas de transição resultantes no segundo aquecimento da amostra na velocidade de $40^{\circ} \mathrm{C} / \mathrm{min}$

\begin{tabular}{ccc}
\hline $\mathrm{R}\left({ }^{\circ} \mathbf{C} / \mathbf{m i n}\right)$ & $\mathbf{T m}\left({ }^{\circ} \mathbf{C}\right)$ & $\mathbf{T i}\left({ }^{\circ} \mathbf{C}\right)$ \\
\hline 10 & $137 / 151$ & 183 \\
12 & $137 / 151$ & 182 \\
14 & $136 / 150$ & 181 \\
16 & $135 / 148$ & 181 \\
18 & $135 / 148$ & 180 \\
20 & $134 / 147$ & 180 \\
\hline
\end{tabular}

$\overline{\mathrm{R} \text { - velocidade de resfriamento, Tm- temperatura de fusão, Ti- temperatura }}$ de isotropização 
As exotermas de cristalização (transição nemático-sólido), obtidas no resfriamento da amostra, foram analisadas pela equação de Ozawa para verificar o mecanismo de cristalização do polímero. Na cinética de cristalização não-isotérmica, o tratamento dos dados envolve o cálculo de $\mathrm{X}(\mathrm{T})$, fração de material cristalizado, da medida das áreas parciais das exotermas obtidas no resfriamento do polímero, na faixa de temperatura onde ocorre a cristalização.

A fração amorfa calculada [1-X(T)] é analisada em função da temperatura para as diferentes velocidades de resfriamento empregadas no estudo cinético. O gráfico da fração amorfa em função da temperatura para o poliéster, cristalizado não-isotermicamente em diferentes velocidades de resfriamento, é mostrado na Figura 3.

Os valores da fração amorfa, [1-X(T)], são determinados em uma temperatura constante do intervalo de temperatura em que ocorre a cristalização no resfriamento, para as diferentes velocidades de resfriamento empregadas. O efeito das diferentes velocidades de resfriamento na cristalização foi observado do gráfico. Quanto maior a velocidade de resfriamento, a faixa de temperatura em que a cristalização ocorre é deslocada para temperaturas mais baixas. A cristalização é controlada pela nucleação, ou seja, em baixas velocidades de resfriamento há tempo suficiente para os núcleos serem ativados em temperaturas mais altas. Consequentemente, a cristalização é nucleada em temperaturas maiores quan-

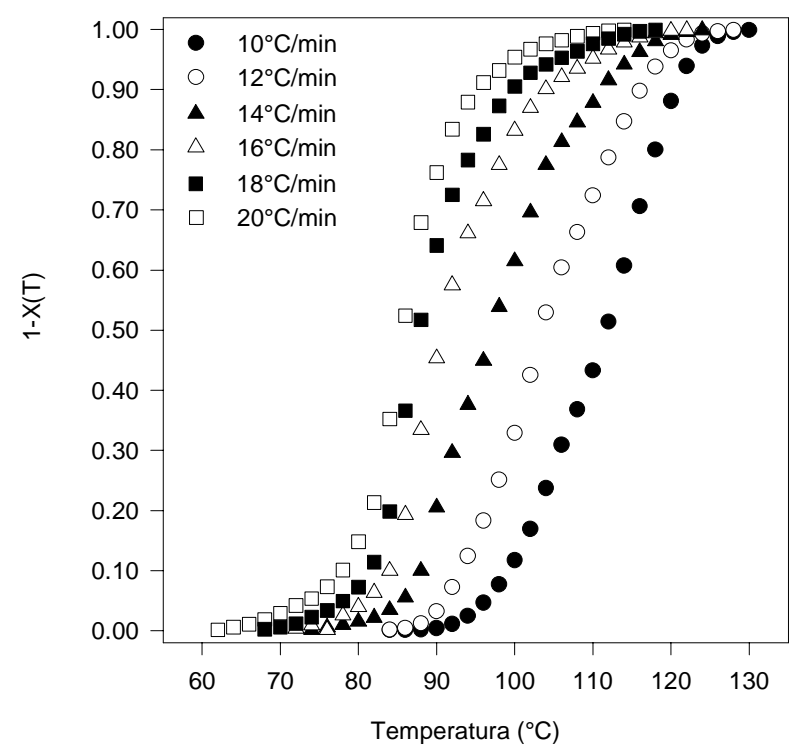

Figura 3. Fração amorfa do poliéster calculado a partir das áreas parciais das exotermas de cristalização obtidas em diferentes velocidades de resfriamento em função da temperatura do as amostras de polímero são resfriadas em velocidades mais baixas. Ao contrário, em velocidades de resfriamento mais altas a ativação dos núcleos ocorre em temperaturas mais baixas.

A teoria de Ozawa permitiu descrever o mecanismo de cristalização do polímero. Os pontos encontrados estão perfeitamente alinhados e forneceram retas que permitiram estimar os parâmetros cinéticos envolvidos no processo de cristalização. A Figura 4 mostra o gráfico com várias isotermas e os parâmetros que caracterizam o mecanismo de cristalização foram estimados. Os expoentes de Avrami $n$ e o parâmetro Q (função da velocidade de cristalização no resfriamento a uma dada temperatura) para o poliéster foram retirados do gráfico.

Foi encontrado que o expoente de Avrami $n$ varia com a temperatura, apresentando uma tendência geral a aumentar com esse parâmetro. As mudanças na inclinação das retas (isotermas) indicam que $n$ não é constante com a temperatura durante o processo de cristalização primária. $\mathrm{O}$ expoente de Avrami aumenta de $4,8 \mathrm{em} 88^{\circ} \mathrm{C}$ para $7,0 \mathrm{em} 116^{\circ} \mathrm{C}$. Uma possível explicação do resultado é devido, provavelmente, a natureza não-isotérmica da análise. A velocidade global de cristalização aumenta à medida que a temperatura diminui. O efeito da colisão dos núcleos pode alterar o valor de $n$. É possível que o valor de $n$ seja diferente em um processo isotérmico de cristalização, já que o mecanismo de cristalização desenvolvido por um material cristalino depende da natureza do processo ou das condições em que é realizado.

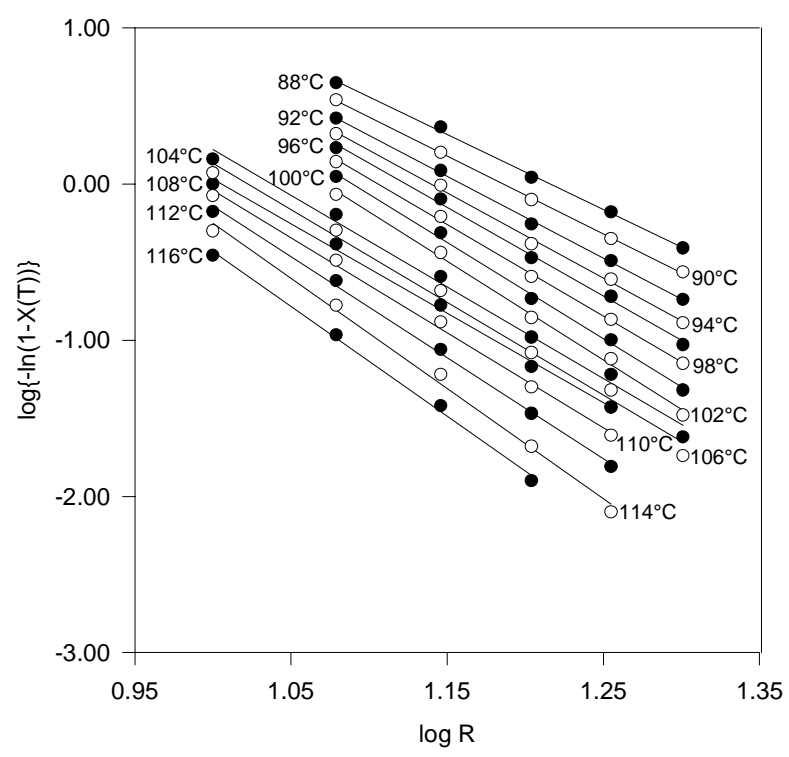

Figura 4. Gráfico de Ozawa em diferentes temperaturas 
Os valores de $\mathrm{n}$ encontrados correspondem a um crescimento de geometria do tipo feixe a partir de núcleos instantâneos e esporádicos. Este crescimento é resultante do término da cristalização primária no estágio inicial de agregação dos feixes sem crescimento esferulítico posterior. Pode-se presumir que essas estruturas sejam formadas devido à velocidade de cristalização alta do poliéster que não permite o desenvolvimento completo em esferulitos ${ }^{[6,11,13]}$. Os valores fracionários de $n$ podem ter se originado da formação simultânea de unidades com crescimento semelhante porém, a partir de núcleos esporádicos e/ ou instantâneos. A mudança no mecanismo de cristalização pode ser devido à velocidade de nucleação e às dimensões críticas dos núcleos, sendo altamente sensíveis às condições de super-resfriamento. Valores de $n$ semelhantes foram encontrados para policapramida ${ }^{[14]}$.

O parâmetro $Q$ foi determinado para cada temperatura do gráfico de $\log \{-\ln [1-\mathrm{X}(\mathrm{T})]\}$ versus $\log \mathrm{R}$. Os valores encontrados na faixa entre 0,8 e 19,1 apresentam uma queda uniforme com o aumento da temperatura. Esses valores estão na mesma faixa daqueles determinados por Ozawa para poli(tereftalato de etileno). Foi verificado por este autor que $\mathrm{Q}$ diminui com o aumento da temperatura. O polipropileno ${ }^{[8]}$ também apresentou a mesma tendência. O significado físico de $\mathrm{Q}$ não tem sido muito discutido, alguns autores acreditam que $\mathrm{Q}$ esteja relacionado à velocidade global de cristalização e indica a velocidade com que ocorre a cristalização dinâmica. Em temperaturas mais altas, a velocidade de cristalização global é baixa.

\section{Conclusão}

A análise de Ozawa permitiu identificar a morfologia do polímero, em forma de feixe, através do estudo da cinética de cristalização não-isotérmica do poliéster, em uma faixa de temperatura bem ampla. Logo, a técnica pode ser utilizada na investigação do comportamento da cristalização de poliésteres termotrópicos semi-flexíveis.

\section{Agradecimentos}

Os autores agradecem ao Conselho Nacional de Desenvolvimento Científico e Tecnológico (CNPq), à Fundação e Coordenação de Aperfeiçoamento de Pessoal de Nível Superior (CAPES), à Fundação de Amparo à Pesquisa do Estado do Rio de Janeiro (FAPERJ) e ao Conselho de Ensino para Graduados e Pesquisa (CEPG/UFRJ) pelo apoio financeiro.

\section{Referências Bibliográficas}

1. Tager, A. -"Physical Chemistry of Polymers", Mir Publishers, cap.5, Moscow, 1978

2. Munich, A. E. - "Atlas of Polymer Morphology", Hanser Publishers, New York, 1993

3. Yeh, S. Y.; Geil, P. H. - J. Macromol. Sci. Phys., B1, 235 (1967)

4. Avrami, M. - J.Chem.Phys., 7, 1103 (1939)

5. Ozawa, T. - Polymer, 11, 150 (1970)

6. Lópes, L. C.; Wilkes, G. L. - Polymer, 30, 882 (1989)

7. Cebe, P.; Hong, S. D. - Polymer, 27, 1183 (1986)

8. Eder, M.; Wlochowicz, A. - Polymer, 24, 1593 (1983)

9. Liu, S.F.; Lee, Y. D. - Macromol. Chem. Phys., 196, 629 (1995)

10. Martins, J. C. A.; Novack, K. M.; Gomes, A. S. Polym. Bull., 36, 369 (1996)

11. Martins, J. C. A.; Novack, K. M.; Gomes, A. S. Pol.: Cienc. e Tecn., jul/set, 44 (1996)

12. Martins, J. C. A. - Tese de Doutorado, IMA/UFRJ, Brasil, (1997)

13. Martins, J. C. A.; Novack, K. M.; Gomes, A. S. Polym. Bull., 37, 497 (1996)

14. Turska, E.; Gogolewski, S. - Polymer, 12, 629 (1971)

Recebido: $20 / 10 / 97$

Aprovado: 11/03/98 